\title{
Foreword
}

\section{Kenneth J. Arrow}

We are indebted to Michael Szenberg's persuasive powers in eliciting the selfanalyses of economists in this and in two preceding volumes. Their existence performs (at least) two functions: interest in their own right as the expressions of a specially capable set of humans outside their technical achievements, and material for the future historian of economic thought.

The writers in this and the earlier volumes constitute a very broad representation of the leaders of economic thought in the last thirty years and more. Being an economist imposes reasonably severe constraints on beliefs, policy positions, and the attitudes towards the fundamental questions that might be said to constitute a 'life philosophy.' Whether these constraints operate by selection or indoctrination, I will leave for those more qualified to judge. But within those constraints, we find a wide variety of self-expressions. As I have observed my colleagues over many years, I find, for example, that their underlying motivations vary greatly. Some enjoy the use of specific tools that they have learned or developed. Some enjoy attempting to resolve intellectual puzzles. Others have strong policy views and visions of social rights and wrongs and engage in analyses designed to reinforce those views. Some are mainly interested in self-advancement, in outdoing others in novelty and distinction. Others have had a saintly or perhaps priestly attitude; the development of economics by whomever and however was the goal.

As may not surprise an economist, motivations do not necessarily affect outcomes; what matters is their strength and the reward system of the academic world. I have known excellent work to be performed by individuals who were concerned about their fidelity to science and also by those whose concern was their own advancement.

Just as diversity in motivation and ideology is compatible with development in economics (or any other science), so is diversity in methodology. Indeed, variety in methodology is positively beneficial. To continue the economic metaphor, there are large gains from trade from a variety of approaches. The most obvious example is the falsity of the empirical-theoretical dichotomy. The roles of empirical evidence in stimulating theory and of theory in guiding empirical inquiry are by now commonplaces as they were not fifty years ago. The increasing tendency to join these approaches in a single paper is to be 
applauded. What is not always recognized, though, is that the differences have roots in personality differences, to be identified in part with 'life philosophies.'

To turn to a different aspect of these self-analyses, many, perhaps most, put great emphasis on the presence of some outstanding teacher or teachers. Indeed, not only in these volumes but in the history of economic thought, we have narratives based on some great original scholar who inspires and teaches disciples. Thus, Marshall trained many economists, most notably, Pigou, Keynes and Robertson, and other economists whose reputations have survived less well. Keynes in turn stimulated his own even more devoted followers Kahn, Joan Robinson and Meade. At Vienna, Carl Menger's teaching was received by Wieser, Böhm-Bawerk and Schumpeter (a pretty formidable trio).

But in a world of publication, influence is not confined to the classroom. Marshall himself drew on John Stuart Mill, who, to the best of my knowledge, never faced a class; and Mill, of course, followed, even slavishly, the work of David Ricardo, not a professor but a retired businessman. W. Stanley Jevons, who certainly is one of the original figures of neoclassical economics, was essentially self-taught. Léon Walras had an economist father; but he seems to have spent his youth trying to find some other occupation; and his work reflects no great influence from his father (though he did use one of his technical terms as a form of piety). Francis Edgeworth, Irving Fisher, Vilfredo Pareto and Knut Wicksell all seem to have acquired their economic knowledge by reading, and they did not have many students whom they inspired. Paul Samuelson was as student at one of the two most important centers of economic research in the United States at the time. Yet I find it hard to detect the influence of his teachers in the central part of his work, though he did have very fruitful contacts with fellow-students. Even in Keynes's case, many of those who most contributed to the further development of his doctrines were not students of his but other economists who were influenced by his writings: the names of Harrod, Hicks, Kaldor and Lerner spring immediately to mind, not to mention the many American followers from Alvin Hansen on.

It would be interesting to examine the essays collected in this and earlier volumes in the same series to see what proportion ascribe a dominant role to one or a few professors and to what extent an outside observer would agree that the professor was in fact influential in the writer's work.

This remark leads back to one made at the beginning of this Foreword - that these essays will be of use to a historian of economic thought. To what extent are essays of this kind reliable evidence? On factual matters, one's memory is not infallible, as I have had occasion to learn to my embarrassment. Do we really know the motives which led us into economics or into our particular research directions? From a practical viewpoint, should we interview elderly scholars about their career and research choices? Recently, one author put out 
an examination of the development of economics since World War II. The book is full of scholarly apparatus. He went into archives and cited them. But he did not interview anyone, even though many of those whom he discusses are still alive. Was this because he felt that the interviews would be selfserving?

I am not so pessimistic. I believe it was Wordsworth who wrote, 'Poetry is emotion recollected in tranquility.' That means the poetry is not conveying fully the original emotion, but it does not mean that we don't learn a good deal, more indeed, than we could from the incoherent expressions of a less tranquil time. We are certainly learning one thing from the essays - what the writer thinks today. But more than that, we get one privileged insight, not the whole truth (which is always unknowable), but one perspective which could not be obtained from any other source than the author.

For these insights, the budding economist as well as the historian of thought should be grateful. 